\title{
Primary Giant Desmoid Tumor of the Chest Wall
}

\author{
El Hassane $\mathbf{K}^{*}$ \\ Department of Thoracic Surgery, Mohamed V Military Hospital, Riad, Rabat, Morocco
}

*Corresponding author: El Hassane K, Department of Thoracic Surgery, Mohamed V Military Hospital, Hay Riad, Morocco, Tel: 212661262637; Email: hassankabiri@yahoo.com

Received date: November 23, 2016; Accepted date: November 28, 2016; Published date: December 02, 2016

Citation: El Hassane K. Primary Giant Desmoid Tumor of the Chest Wall. Arch Med. 2016, 8:6

Copyright: (C) $2016 \mathrm{El}$ Hassane K. This is an open-access article distributed under the terms of the Creative Commons Attribution License, which permits unrestricted use, distribution, and reproduction in any medium, provided the original author and source are credited.

\begin{abstract}
We here report the case of 42 years old women with a huge tumor of the anterior chest well, the chest CT scan showed the tumor with large contact with the intercostal spaces. A surgery was scheduled and allowed total removal after a laborious dissection and surgical techniques were necessary to remove this tumor. The pathologist confirmed the diagnosis of desmoid tumor.
\end{abstract}

\section{Keywords: Tumor; Surgery; Thoracotomy; Biopsy}

\section{Case Report}

A 46 years old woman was admitted in our department after 16 months history of progressive chest wall mass. Physical exam noted a mass of the left anterolateral chest wall (Figure 1). The chest-CT showed a well limited heterogeneous solid contrastenhanced mass of $31 \mathrm{~cm}$.

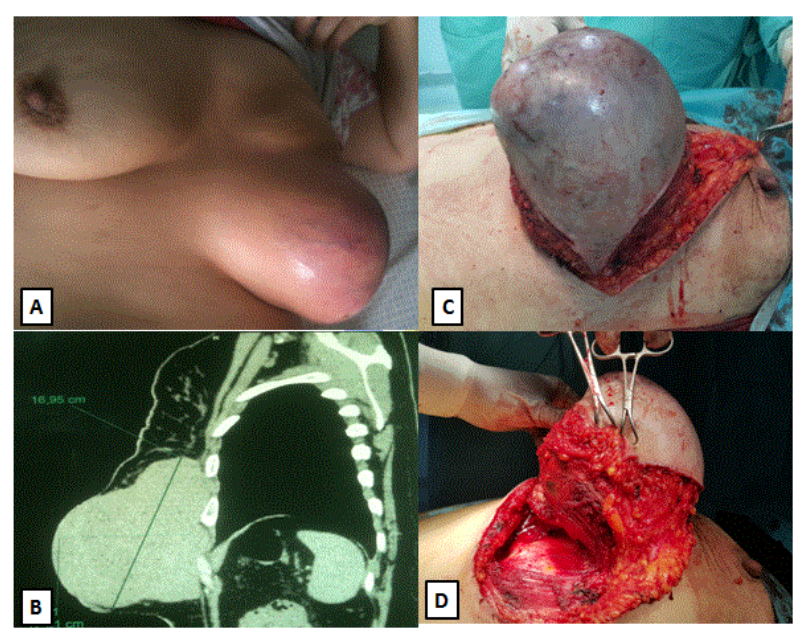

Figure $1 \mathrm{~A}$ ) Macroscopical view of the mass, B) Chest CT scan showing the chest wall mass, C) Pre-operative view of initial mass dissection, D) Pre-operative view of intercostal and costal time dissection of the mass.
The mass described an intercostal involvement without costal lysis. Pre-operative needle biopsy made a definitive diagnosis of fibromatosis (Figure 2).

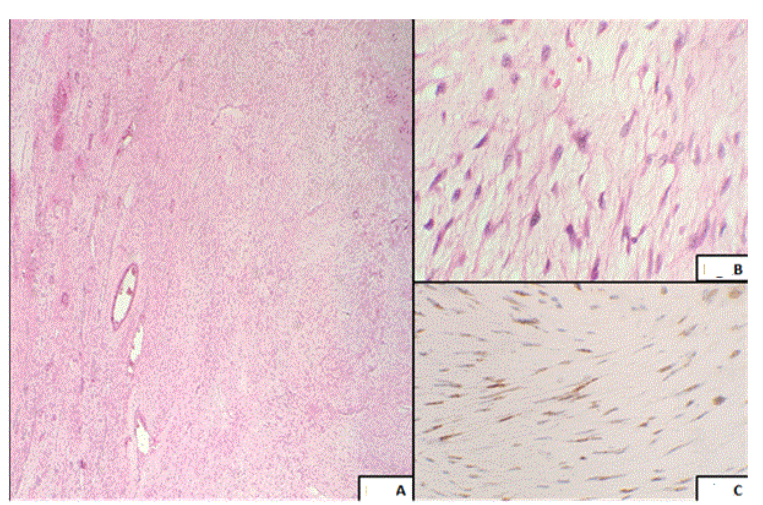

Figure 2 A) Uniform bands of spindle shaped cells arranged in fascicles admixed with blood vessels (H\&E; magnification $X 40), B)$ Spindle and stellate cells with interspersed collagen matrix ( $\mathrm{H}$ and $\mathrm{E}$; magnification $\mathrm{X} 400$ ), C) Immunostaining for beta-catenin shows nuclear expression (magnification X400).

A surgical resection was performed through an elective thoracotomy. Post-operative course was uneventful. The following up noted no recurrence after one year.

Desmoid tumor of the chest wall is very rare and locally aggressive but has no distant metastasis. Radical surgical resection was the standard treatment before 2000, because negative margins after complete excision was considered to be the primary goal, such as indicated for malignant tumors sarcomas [1]. Nowadays, surgery is discussed, because the excision can allow consequences worse than the disease itself. Besides, some tumors recur after excision, but then remain stable without treatment, suggests that growth factors released following surgery may promote recurrence.

Post-operative radiotherapy did not reduce the recurrence rate [2]. We insist that when the tumor is huge and locally aggressive and unaesthetic, surgery is recommended. 


\section{Conclusion}

We report this case to emphasize that surgery is the only way to remove and cure such huge tumors. The recurrent character of this kind of tumor even with total removal should be always in mind.

\section{References}

1. Foa R, Rizzo S, Petrella F, De Maria F, Bellomi M (2014) Recurrent aggressive fibromatosis of the chest wall. Ecancermedicalscience 8: 464 .

2. Ma D, Li S, Fu R, Zhang Z, Cui Y, et al. (2016) Long-term outcomes of 47 patients with aggressive fibromatosis of the chest treated with surgery. Eur J Surg Oncol 42: 1693-1698. 